\title{
Effect of Soil-Structure Stabilizers on the Production of Tobacco Plants in the Seedbed
}

\author{
M. A. Lugo-López, J. A. Bonnet, A. S. Amy, and R. Pérez-Escolar ${ }^{1}$
}

\section{INTRODUCTION}

Surface-crusting is usually a problem of major importance in tobacco seedbeds. It interferes mainly with seedling emergence and to some extent with the subsequent growth and development of the young plants. In Puerto Rico, many soils used for tobacco seedbeds have a high clay content, and compact and crust rather badly, often exhibiting undesirable physical conditions $(4)^{2}$. Now that synthetic soil-structure stabilizers have appeared in the market attention has been directed to their ability to decrease the surface-crusting of soils $(1,3)$. Since 1952 considerable work along this line has been conducted in the major tobacco-producing areas of the United States (2).

This paper reports the results of two field studies designed to determine the effect of several polyelectrolyte soil-structure stabilizers on the emergence and survival of tobacco seedlings. Filter-press cake, a byproduct of the sugar mills which can be obtained free and worked into the soil at a relatively low cost, was included among the treatments to evaluate its effect and to provide a practical basis for analyzing the effects of the synthetic stabilizers.

\section{MATERIALS AND METHODS}

Two experiments were conducted, one in 1952-53 and another in 1953-54, at nearby sites on an acid Caguas clay loam at one of the Tobacco Substation farms, on the outskirts of Caguas. The plant beds in both cases were protected with cheesecloth and were irrigated by sprinkling whenever required. The 1952-53 experiment included five treatments in a Latinsquare design. The plots were 3 by 8 feet. A 6-8-10 fertilizer was applied to the soil at the rate of 1,500 pounds to the acre and hydrated lime was used at the rate of 1 ton to the acre. The seed were sown during the last week of November and the harvest or pulling of seedlings began on Jan-

1 Associate Soil Scientist, Head of the Department of Soils, Associate Agronomist in charge of the Gurabo (Tobacco) Substation, and Research Assistant in Soils, respectively, Agricultural Experiment Station, University of Puerto Rico, Rio Piedras and Gurabo, P. R.

2 Italic numbers in parentheses refer to Literature Cited, p. 196. 
uary 14, extending until late in February. The materials applied were as follows:

1 , None

2, Filter-press cake, 25 ton/A. (dry basis)

3, Krilium, formulation 6, 100-percent active ingredient, 3,600 lb./A.

4, Krilium, formulation 9, 100-percent active ingredient, 3,600 lb./A.

5, Aerotil, 40-percent active ingredient, 3,600 lb./A.

The synthetic conditioners, all in their powdered dry form, were thoroughly mixed with the topmost 3 inches of soil and the filter-press cake was worked into the surface 6-inch layer. The check plots received the same mechanical treatment as the stabilizer-treated plots to minimize any possible differences other than those imposed by the conditioners.

The 1953-54 experiment was laid out following a balanced incompleteblock design. The plots were again 3 by 8 feet. There were seven treatments each replicated six times. The materials applied were as follows:

1 , None

2, Filter-press cake, 25 ton/A. (dry basis)

3 , Krilium, formulation 6,100-percent active ingredient

4, Krilium, formulation 9, 100-percent active ingredient

5, Aerotil, dry form, 40-percent active ingredient

6, Goodrite, $\mathrm{K} 700 \mathrm{WF}$, flakes, 87-percent active ingredient

7, Goodrite, $\mathrm{K} 700 \mathrm{~S}$, liquid, 17.4-percent active ingredient

The synthetic stabilizers were applied on the basis of a 0.02-percent concentration, i.e., a total of 60 pounds of active ingredient of each chemical to the acre. The treatments were applied on October 19,1953, when the soil was almost completely dry. The filter-press cake (treatment 2) was worked into the top 6 inches of soil while the synthetic stabilizers were worked into the uppermost 1 inch of soil. The soil in the check plots was stirred to a 1-inch depth to minimize differences other than treatments. Sterile sand was used as a carrier for the dry powdered stabilizers (Krilium 6 and 9, Aerotil, and Goodrite K $700 \mathrm{WF}$ ) while the liquid Goodrite, K $700 \mathrm{~S}$, was diluted in 1 gallon of water and sprayed finely over the surface. The seed were sown 3 days after applying the treatment differentials and the soil was irrigated through sprinkling afterwards. Before the application of the stabilizers, Aldrin was applied at the rate of 2 pounds to the acre and a 6-8-10 fertilizer over the surface at a rate of 1,200 pounds to the acre. Hydrated lime was applied as in the previous experiment. The first batch of plants was pulled on December 2, 1953, and the last on February 9 , 1954, comprising a total of six pullings. A number of seedlings from the third pulling were planted under field conditions and observations were made as to setting, vigor, and development. 


\section{RESULTS AND DISCUSSION}

Table 1 gives data on seedling production from the 1952-53 and 1953-54 experimental plant beds. There were highly significant differences among treatment means. No significant differences were obtained between the check, the filter-press-cake-treated plots, and the Aerotil-treated plots

TABLE 1.-Mean number of tobacco seedlings obtained in 1952-53 and 1958-54 when soil-structure stabilizers were added to seedbeds

\begin{tabular}{l|c|c}
\hline \multicolumn{1}{c|}{ Treatment } & Rate & Seedlings per acre \\
\hline & $1952-58$ Experiment & \\
\hline & Lb. per ocre & Number \\
Check & 0 & $3,339,963$ \\
Filter-press cake & 50,000 & $3,541,428$ \\
Krilium 6 & 3,600 & $2,876,775$ \\
Krilium 9 & 3,600 & $2,382,732$ \\
Aerotil & 3,600 & $3,260,103$ \\
\hline \hline L.S.D. at the 5-percent level & & 398,138 \\
L.S.D. at the 1-percent level & & 558,203 \\
\hline
\end{tabular}

1958-54 Experiment

\begin{tabular}{l|r|r}
\hline Check & 0 & 497,310 \\
Filter-press cake & 50,000 & 820,380 \\
Krilium 6 & 60 & 336,138 \\
Krilium 9 & 60 & 673,002 \\
Aerotil & 60 & 842,160 \\
Goodrite, flakes & 60 & 870,656 \\
Goodrite, liquid & 60 & 941,440 \\
\hline \hline L.S.D. at the 5-percent level & & 515,896 \\
L.S.D. at the 1-percent level & 692,259 \\
\hline
\end{tabular}

However, all three outyielded the plots treated with both Krilium formulations. It must be recalled that the Aerotil contains only two-fifths of the same active ingredient as Krilium 9, hence, much less active chemical was actually applied when the experiment was laid out. Both Krilium formulations were highly detrimental to the emergence of tobacco seedlings in these experimental seedbeds. Rather large bare spots were observed in the plots adversely affected (fig. 1). The young seedlings, however, were healthy in all cases and were not adversely affected by treatment with any of the structure stabilizers tested. 
The data obtained from the 1953-54 experiment are also summarized in table 1. Some significant differences could be detected upon statistical analyses of the data. Both Goodrite formulations were superior to Krilium 6 which seemed to exert harmful effects even at the low rates used (0.02percent active ingredient in all cases) in this experiment.

As shown in table 2 the filter-press cake induced a quicker emergence and development of the seedlings (fig. 2). By the time of the second pulling,

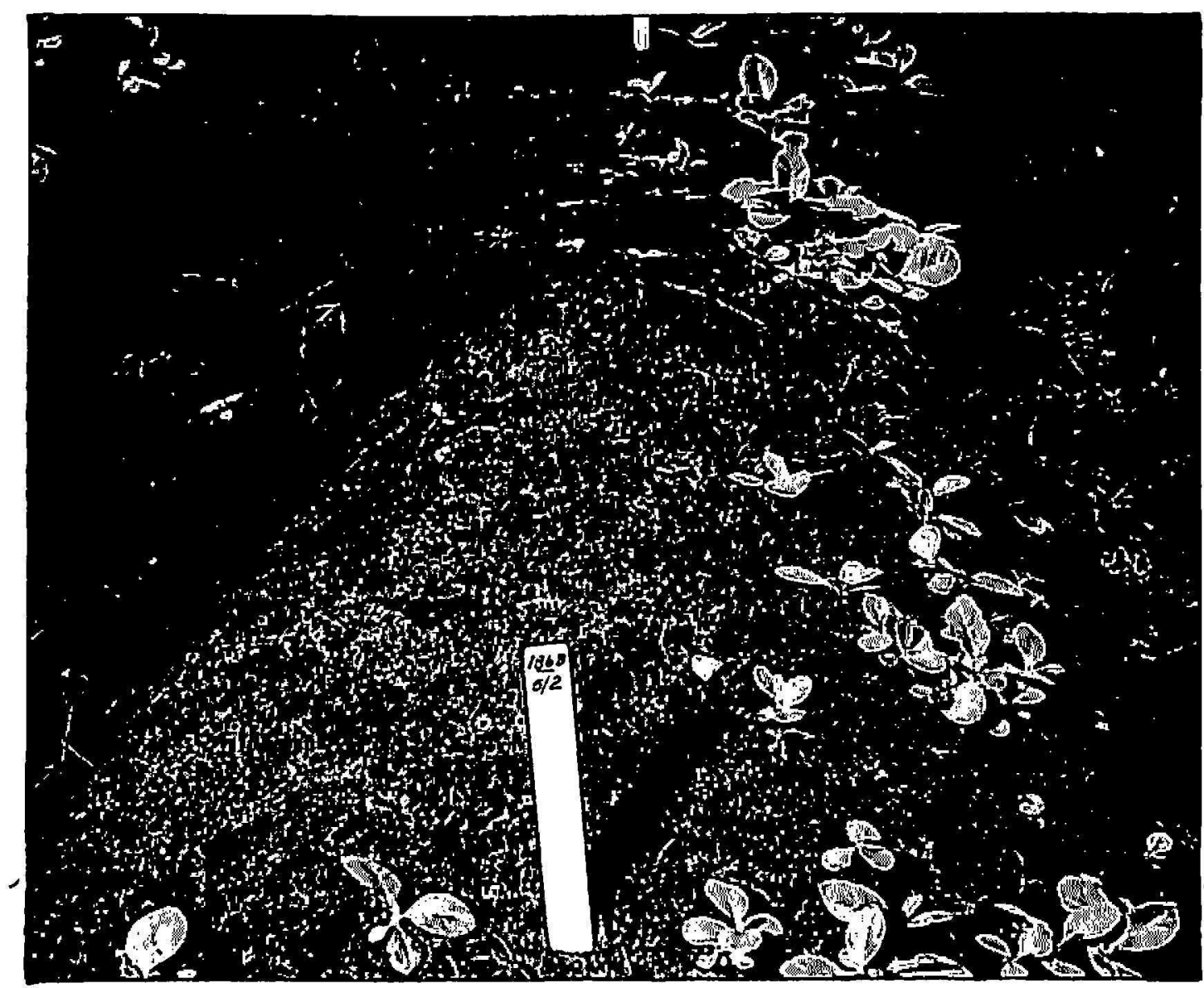

Fig. 1.-Large bare spots occurred in some of the conditioner-treated plots.

about 70 days following sowing, over 40 percent of the seedlings could be pulled from the filter-press-cake-treated plots, while only 20 percent could be pulled in the next best treatment, and only 7 percent in the untreated plots. These earlier maturing seedlings were also apparently healthier and more vigorous and their root systems were better developed (fig. 3). However, observations made from a selected group of plants that were transplanted to field conditions from each treatment failed to disclose any relevant differences as to survival, vigor, development, and production. Nevertheless, this earliness might be of tremendous practical and economic importance to the farmer, since field plantings must be established and 
handled early in autumn in order to conclude the harvesting and curing during the spring.

An over-all examination of the data from both experiments suggests that the tobacco-seedling stands were somewhat adversely affected by some

TABLE 2.-Influence of filter-press cake and synthetic soil-structure stabilizers upon the age at which seedlings could be pulled from seedbeds for transplanting to the field

\begin{tabular}{l|r|r|r|r|r|r}
\hline \multirow{2}{*}{ Treatment } & \multicolumn{5}{|c}{ Percentage of seedlings pulled at indicated age, in days } \\
\cline { 2 - 7 } & \multicolumn{1}{|c|}{32} & \multicolumn{1}{|c|}{45} & 55 & 60 & \multicolumn{1}{c}{73} & \multicolumn{1}{c}{100} \\
\hline Check & 1.5 & 5.8 & 41.3 & 21.0 & 16.8 & 13.6 \\
Filter-press cake & 15.1 & 27.8 & 33.8 & 10.4 & 5.8 & 7.1 \\
Krilium 6 & 1.2 & 7.8 & 37.1 & 23.8 & 21.1 & 9.0 \\
Krilium 9 & 2.8 & 14.6 & 45.1 & 17.4 & 9.2 & 10.9 \\
Aerotil & 5.0 & 12.5 & 41.3 & 19.9 & 9.6 & 11.7 \\
Goodrite, flakes & 4.2 & 16.4 & 45.7 & 16.5 & 8.5 & 8.7 \\
Goodrite, liquid & 2.9 & 9.5 & 45.1 & 17.5 & 10.6 & 14.4 \\
\hline
\end{tabular}

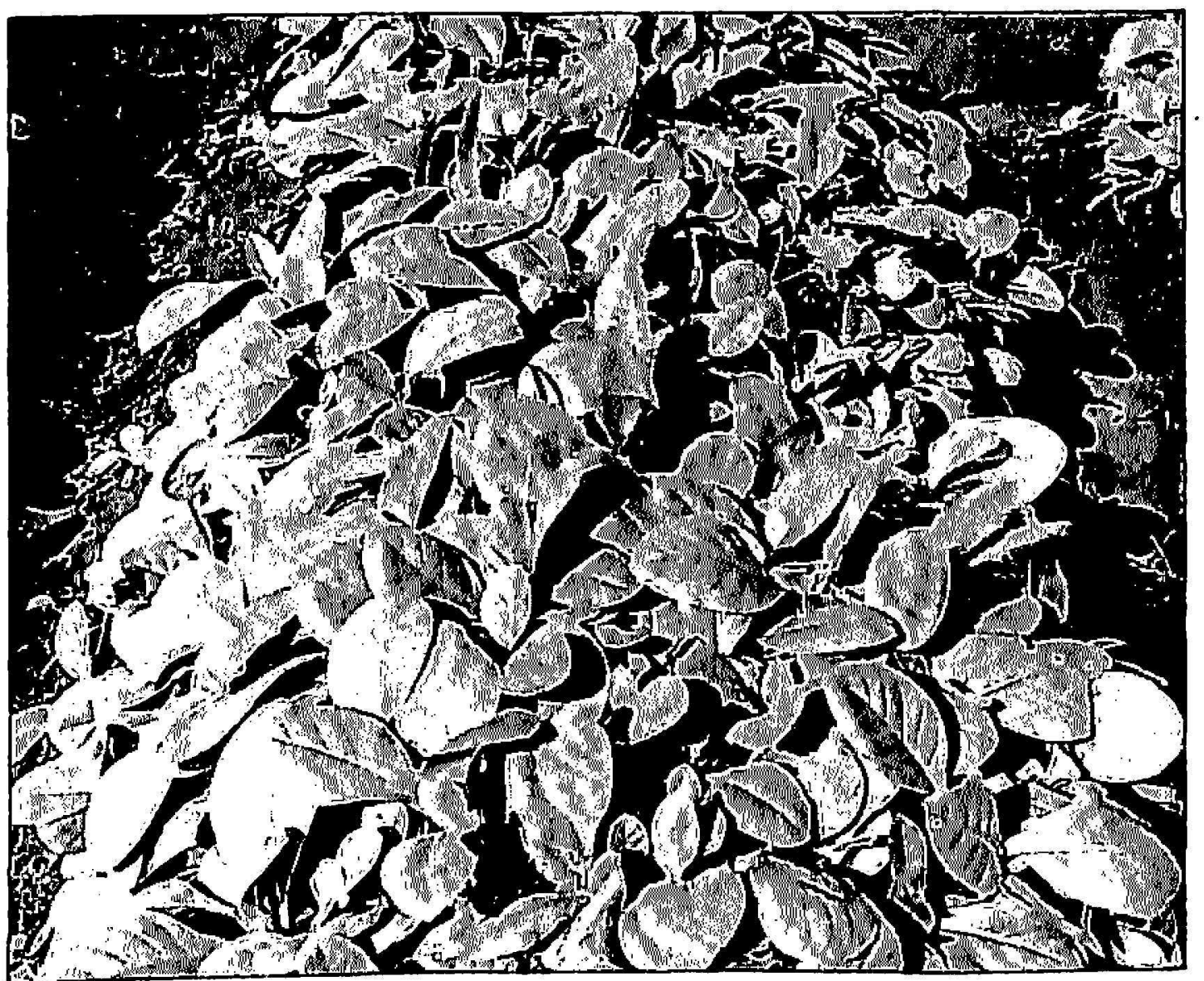

Fig. 2.-Appearance of filter-press-cake-treated plant beds some 37 days after sowing. 
of the synthetic soil-structure stabilizer treatments. This was particularly evident in the plots treated with both Krilium formulations at the high levels used in the 1952-53 experiment and in the Krilium 6-treated plots in the 1953-54 experiment. If Aerotil had been used at the same concentrations, on an active-ingredient basis, probably the same harmful effects would have been observed since it contains the same basic constituent as

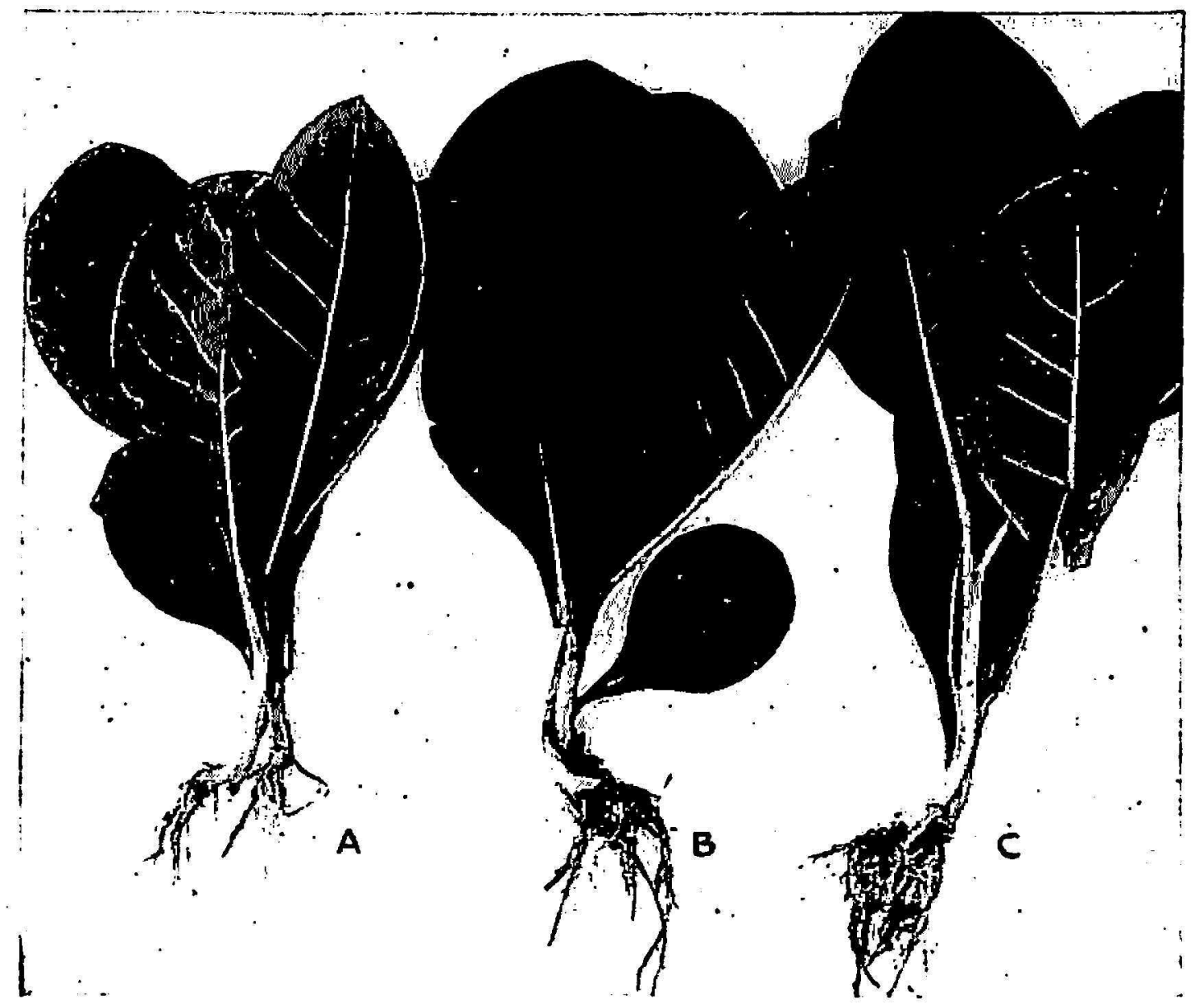

FIG. 3.-Although the seedlings from the conditioner and filter-press-cake-treated plots seemed larger and with better developed root systems than those from check plots, no differences were observed when they were transplanted to field conditions: A, Check; B, filter-press-cake-treated; C, Goodrite-treated.

Krilium 9, although the difference in the carriers used as diluents might modify this effect considerably. The harmful effects of the stabilizers may be a reflection of the observed marked surface drying in the plots with a better soil structure.

It does not appear from these tests that these synthetic materials have economic possibilities in tobacco-plant beds. This is further emphasized by their almost prohibitive current prices. However, they might effectively reduce hard soil crusts, thus favoring seedling emergence, in soils with more acute crusting tendencies than the one where these tests were carried on. 
For earlier maturing seedlings the use of filter-press cake should be advocated. It can be obtained free from sugar mills and incorporated into the soil at a reasonably low cost.

\section{SUMMARY}

Data are presented here from two experiments on the effect of synthetic soil-structure stabilizers and filter-press cake on tobacco seedbeds. The materials used in an experiment performed in 1952-53 were: None; 25 tons to the acre of filter-press cake; and Krilium 6, Krilium 9, and Aerotil, each at the rate of 3,600 pounds to the acre of the dry powdered form. In an experiment performed in 1953-54 the same stabilizers were used with the addition of Goodrite in both the flakes and liquid forms. However, all stabilizers were applied on the basis of a 0.02 -percent concentration of the active ingredient. The number of seedlings obtained from the check plots, filter-press-cake-treated plots, and Aerotil-treated plots were significantly higher than those obtained from plots treated with both Krilium formulations in the 1952-53 experiment. Significant differences were measured in the 1953-54 experiment favoring both Goodrite formulations as compared with Krilium 6, at the low rate at which the synthetic stabilizers were applied. Filter-press cake seemed effective in inducing a quicker emergence and adequate development of the seedlings.

\section{RESUMEN}

Se presentan aquí datos de dos experimentos en los cuales se estudió el efecto de estabilizadores sintéticos de la estructura del suelo y de la cachaza en el desarrollo de las plantitas en semilleros de tabaco. En el primer experimento se usaron los siguientes tratamientos: Nada, 25 toneladas de cachaza por acre y Krilium 6, Krilium 9 y Aerotil, todos en forma de polvo seco y a razón de 3,600 libras por acre. En el segundo experimento, además de los productos antes mencionados se incluyó Goodrite, en sus formas de hojuelas y líquido; pero todos los estabilizadores se aplicaron a base de una concentración de 0.02 porciento de su ingrediente activo.

El número de plantitas obtenidas de las parcelas testigo y de las que recibieron cachaza o Aerotil sobrepasó significativamente el que se obtuvo de las parcelas tratadas con Krilium 6 ó 9 en el primer experimento. Se midieron diferencias significativas en el número de plantitas obtenidas en el segundo experimento las cualas favorecen el uso de ambas formulaciones de Goodrite, al compararlas con Krilium 6 a la concentración usada. El uso de la cachaza en los semilleros de tabaco parece eficaz, ya que induce una germinación más rápida y un desarrollo adecuado de las plantitas. 


\section{LITERATURE CITED}

1. Heddrick, R. M., and Mowry, D. T., Effect of synthetic polyelectrolytes on aggregation, aeration, and water relationships of soils, Soil Sci. 73(6) 427-41, 1952.

2. Jamison, V. C., Subcommittee reports on soil conditioners to the Southern Regional Soil Research Committee, 1952, 1953, and 1954 (mimeographed), Auburn, Ala.

3. Pearson, R. W., and Jamison, V. C., Improving land conditions for conservation and production with chemical soil conditioners, $J$. Soil \& Water Conserv. 8(3) 130-5, 1953.

4. Roberts, R. C., Soil survey of Puerto Rico, USDA in cooperation with Univ. of P. R. Agr. Exp. Sta., Series 1936 (8), 1942. 